\title{
PEMBELAJARAN KALĀM DENGAN MEDIA MUSIK (LAGU)
}

\section{Nurul Hikmah*}

Pusat Pengembangan Bahasa Arab UIN Malana Malik Ibrahim Malang Email: taklimmsaa@gmail.com

\section{مستخلص البحث}

اللغة العربيّة هي احدى من اللّغات العالميّة المهمّة لنا، في عمليّة تعليمها وجد

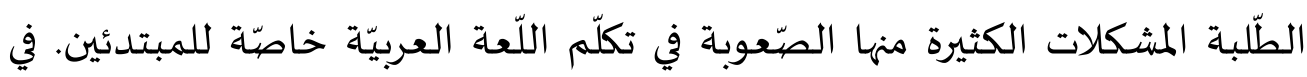
مواجهة هذه المشكلة حلّ المعلّمون تعليم مهارة الكلام باستخدام الموسيق (الغناء).

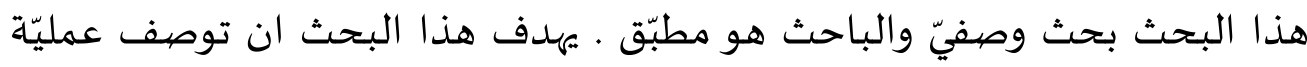
تعليم مهارة الكلام للطّلبة غير ناطقين با للغة العربيّة باستخدام الموسيق (الغناء)

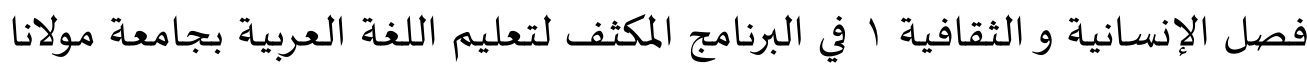
مالك إبراهيم الإسلاميّة الحكومية بمالانج · ونتائج البحث تدلّ على أنّ استخدام

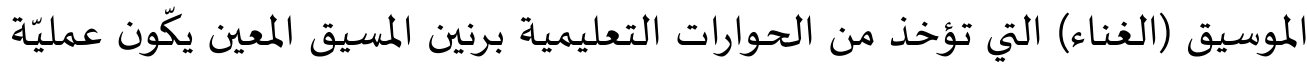

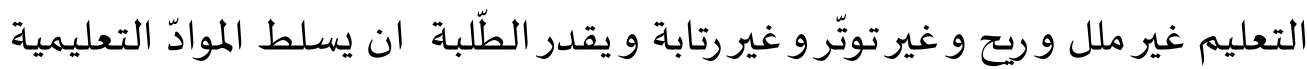

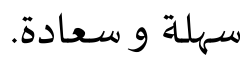
الكلمات الرئيسية : وسيلة التعليم، الموسيق(الغناء)، الكلام.

\section{PENDAHULUAN}

Bahasa Arab adalah salah satu bahasa internasional yang penting di dunia ini dan harus dipelajari, untuk mempelajarinya kadang ada beberapa kendala yang dihadapi oleh pembelajar, diantaranya adalah kesulitan mengungkapkan kalimat berbahasa Arab, khususnya bagi kalangan pemula. Dalam menghadapi kendala ini, ada yang bisa menghadapinya dan ada yang belum bisa menghadapinya, bahkan kadang dengan kendala ini membuat orang putus asa dan bosan dalam mempelajari kalam berbahasa Arab, karena itu penting kiranya bagi 
pengajar membuat terobosan baru untuk menyelesaikan masalah ini yaitu dengan menggunakan media yang membuat pembelajaran kalam berbahasa Arab menjadi menyenangkan, mudah dan tidak membosankan, seperti yang kita tahu media berperan penting dalam proses pembelajaran, materi yang sulit bisa menjadi mudah disampaikan dengan menggunakan media.

Belajar bahasa Arab ada kalanya mudah bagi beberapa orang dan adakalanya sulit bagi beberapa orang lainya. Menyenangkan mungkin karena belajar bahasa Arab dengan metode yang mudah, pengajarnya menyenangkan, dan medianya sesuai sehingga belajar bahasa Arab tidak membosankan. Bagi sebagian lain belajar bahasa Arab terasa sulit karena bahkan menyusahkan karena metode yang digunakan dalam belajar bahasa Arab rumit, pengajarnya tidak kreatif, monoton, dan media yang digunakan tidak sesuai, awal-awal pembelajaran mereka para pembelajar semangat untuk belajar lama-kelamaan karena belajarnya membosankan semangat mereka berkurang, dan berdampak pada kehadiran mereka dikelas.

Keadaan semacam ini harus dicarikan solusinya agar pembelajaran bahasa Arab menjadi menyenangkan, karena pentingnya bahasa Arab bagi umat Islam, kalau sudah tidak suka maka sulit untuk bisa mahir berbicara berbahasa Arab merupakan keterampilan berbahasa yang banyak diinginkan para pembelajar bahasa Arab, jarang memang ada orang yang mampu menguasai 4 keterampilan bahasa sekaligus yaitu istimā', kalām, qirā'ah, kitābah, ada kalanya dalam keterampilan menyimak bagus karena sering bergulat dengan bahasa Arab jadi dalam pendengaranya sudah sangat peka dengan menyimak orang lain berbahasa Arab atau mungkin karena dia tinggal di lingkungan orang Arab maka sangat mudah sekali untuk terampil menyimak karena sudah 
menjadi kebiasaan , kadang lemah di kalām karena banyak mufrodat yang belum dikuasai, kadang lemah di qirā'ah karena minim membaca bukubuku berbahasa Arab, kadang kelemahanya di kitābah (menulis bahasa Arab karena belum maksimalnya ilmu imlä' yang erat hubunganya dengan nahwu sharaf.

Dalam proses pengajaran bahasa Arab sebagai bahasa asing orang Indonesia, ada beberapa hal yang perlu diperhatikan agar bisa meraih keberhasilan, beberapa hal itu adalah pengajar, pembelajar, metode pengajaran dan media pembelajaran. Pengajar harus banyak memotivasi pembelajar agar tetap tekun dan tidak jemu mempelajari bahasa Arab, mengajar dengan cara baik dan benar, tidak monoton, tetapi harus kreatif dan inovatif serta bersabar dalam menghadapi tantangan yang ada, pembelajar harus berniat ikhlas, berdoa kepada Allah agar diberikan kemudahan dalam belajar bahasa Arab dan istiqamah dalam belajar , tidak mudah jemu, tidak berputus asa tekun dan giat dalam belajar, saling memotivasi antar pembelajar juga penting dalam proses pembelajaran bahasa Arab. ${ }^{1}$

Metode yang digunakan dalam pembelajaran bahasa Arab juga harus mudah, benar dan terus mengikuti perkembangan jangan sampai mengesankan bahasa Arab sulit untuk menjadikan pembelajaran bahasa Arab menyenangkan maka dibutuhkan media, media yang digunakan harus bermacam-macam dan beragam sesuai perkembangan teknologi harus diperhatikan agar pesan pembejaran bisa tersampaikan dengan baik. Dalam upaya agar pengajaran bahasa Arab mencapai keberhasilan, dalam tulisan ini penulis akan mendeskripsikan bagaimana musik (lagu) sebagai media pembelajaran kalām dalam proses pembelajaran di kelas

1 R. Umi Baroroh, Umi, Lagu Sebagai Model Pembelajaran Bahasa Arab untuk Anak dan Pemula, Yogyakarta: Pustaka Zeedny, 2011 hal 17 
Nurul Hikmah: Pembelajaran Kalam Dengan Media Musik (Lagu)

Humaniora 1, 2 dan 3 semester 1 Pusat Pengembangan Bahasa Arab UIN Maulana Malik Ibrahim Malang.

Manfaat musik sebenarnya tergantung pada cara kita menggunakannya, kapan dan apa saja jenis musiknya. Berikut penggunaan musik dalam proses pembelajaran.

1. Musik digunakan sebagai pembukaan sehingga pada waktu yang sesuai akan sangat membantu mempengaruhi perhatian siswa di awal proses pembelajaran.

2. Musik digunakan sebagai pembatas waktu, contonya ketika guru memberikan tugas kepada siswa, maka guru dapat membatasi waktu untuk mengerjakan tugas sampai selesai musik tersebut.

3. Musik digunakan untuk membangkitkan semangat dan energi, saat suasanakelas sedang menurun, siswa sudah mulai mengantuk, bosan, atau letih mainkan musik dengan tempo yang tinggi sambil melakukan gerak badan atau brain gym.

Secara garis besar terdapat perbedaan antara belajar dengan menggunakan musik dan tanpa menggunakan musik dapat dilihat di tabel di bawah ini:

\begin{tabular}{|l|l|}
\hline $\begin{array}{l}\text { Denyut nadi dan tekanan darah } \\
\text { meningkat sehingga otak menjadi } \\
\text { tegang sulit untuk menerima } \\
\text { materi pelajaran }\end{array}$ & $\begin{array}{l}\text { Deyut nadi dan tekanan darah } \\
\text { rendah sehingga otak menjadi } \\
\text { relaks dan mudah untuk } \\
\text { menerima materi pelajaran. }\end{array}$ \\
\hline $\begin{array}{l}\text { Gelombang otak semakin cepat } \\
\text { sehingga akan mengakibatkan } \\
\text { pesan yang sudah disampaikan ke } \\
\text { otak akan cepat hilang dan tidak } \\
\text { tersimpan ke longthrem memory. }\end{array}$ & $\begin{array}{l}\text { Gelombang otak melambat } \\
\text { sehingga siswa akan meyimpan } \\
\text { materi yang telah disampaikan } \\
\text { sampai ke longthrem memory. }\end{array}$ \\
\hline
\end{tabular}


Nurul Hikmah: Pembelajaran Kalam Dengan Media Musik (Lagu)

\section{Pembelajaran Kalam}

Kalām (ungkapan secara lisan) adalah seni memindah pikiran, perasaan, informasi, pengetahuan, pengalaman, ide, pendapat dari sesorang kepada yang lain. Perpindahan ini terjadi pada pendengar, orang yang dihadapi, orang yang diajak bicara disertai terjadinya penerimaan, kefahaman, interaksi dan respon. ${ }^{2}$

Manusia sebagai makhluk sosial selalu berkomunikasi untuk mempertukarkan pengalaman, pikiran, perasaan, dan mengekspresikan segala hal. Kalām sebagai keterampilan berbicara merupakan kemampuan mengucapkan bunyi-bunyi artikulasi atau kata-kata untuk mengekspresikan, menyatakan serta menyampaikan pikiran, gagasan, dan perasaan. Selain itu juga, berbicara merupakan suatu bentuk perilaku manusia yang memanfaatkan faktor-faktor fisik, psikologis, neurologis, semantik, dan linguistik sedemikian ekstensif, secara luas sehingga dapat dianggap sebagai alat manusia yang paling penting bagi kontrol sosial. ${ }^{3}$

Prinsip umum yang mendasari kegiatan berbicara antara lain: (1) ada pembicara dan pendengar; (2) penggunaan sandi linguistik yang dipahami; (3) Adanya penerimaan referensi umum; (4) pertukaran partisipan; (5) konteks tempat; (6) berhubungan waktu; (7) keterlibatam organ bunyi bahasa dan pendengaran; (8) pelambangan bunyi. ${ }^{4}$ Keterampilan berbicara pada anak merupakan bagian kompetensi yang harus dilatih dan dapat dipraktekkan dengan baik dan benar. Berbicara dalam kelas dilakukan dengan membiasakan anak melakukan percakapan dengan bahasa Arab mengunakan tema yang sudah disepakati.

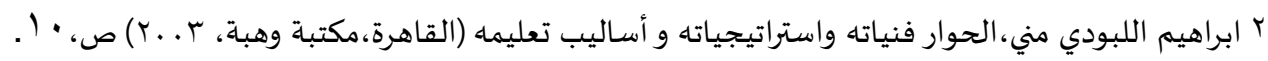

3 Rahmaini. Strategi Pembelajaran Maharah Kalam Bagi Non Arab. Jurnal Ihya U1 Arabiyyah Vol 2 Tahun 2015. h, 228

4 Aziz Fachrurrozi, dan Erta Mahyuddin. Teknik Pembelajaran Bahasa Arab. Bandung: Pustaka Cendikia, 2011. h, 129 
Nurul Hikmah: Pembelajaran Kalam Dengan Media Musik (Lagu)

Percakapan dilakukan paling sedikit oleh 2 orang, dan dapat dilakukan secara berkelompok.

\section{Media Musik}

Media berasal dari bahasa latin "medius" yang secara harfiah berarti tengah, perantara, atauPengantar. Secara lebih khusus dalam proses pembelajaran media diartikan sebagai alat-alatGrafis, fotografis, atau elektronis untuk menangkap, memproses, dan menyusun kembal Informasi visual atau verbal. ${ }^{5}$ Dalam konteks belajar dan pembelajaran, media adalah segala sesuatu yang dapatMenyalurkan pesan atau materi ajar dari guru sebagai komunikator kepada siswa sebagai komunikan dan sebaliknya. ${ }^{6}$ Media menjadi alat yang berfungsi untuk menyampaikan pesan pembelajaran pada proses komunikasi antara pembelajar dan pengajar dalam menyampaikan bahan ajar. Komunikasi tidak akan berjalan efektif tanpa bantuan sarana penyampaian pesan yaitu media.

Musik dapat menjadi pilihan media yang apik dalam pembelajaran. Dkk menyebutkan media lagu pada pembelajaran dapat meningkatkan motivasi dan peningkatan kemampuan keterampilan. Pengajar juga berperan aktif dalam pembelajaran, dengan member motivasi kepada anak, menggunakan variasi metode, memanfaatkan media khususnya lagu, dan mengatur alokasi waktu agar perencanaan pembelajaran berjalan dengan baik. ${ }^{7}$

Musik mempunyai hubungan dengan perkembangan kepribadian fisik dan psikis anak. Mulai dari dalam kandungan, kelahiran, sampai

5 Hermawan S, Stephanus, Mudah Membuat Aplikasi Android. Yogyakarta: Andi Offset, 2011. h,233

6 Abdorrakhman Gintings. Esensi Praktis Belajar dan Pembelajaran, Bandung: Humaniora, 2010, h,140

7 Jumaryatun, dkk. Penggunaan Media Lagu Sebagai Upaya Meningkatkan Motivasi Dan Kemampuan Menulis Cerpen. Basaastra Jurnal Penelitian Bahasa Sastra Indonesia dan Pengajarannya Vol 1 No 3 2014, h, 512 
Nurul Hikmah: Pembelajaran Kalam Dengan Media Musik (Lagu)

perkembangan anak. Musik yang sesuai dengan tema materi pembelajaran dapat menumbuhkan karakter anak. ${ }^{8}$ Menurut Ortiz dalam penggunakan musik dalam pembelajaran berguna untuk: 1). Memotivasi anak untuk berlatih, 2). Meningkatkan kepekaan pada tubuh, 3). Mengaktifkan tumbuhnya keterampilan motorik besar, 4). Meningkatkan koordinasi, 5). Mengembangkan rasa percaya diri dan harga diri, 6). Bertindak sebagai katalis untuk improvisasi imajinatif, 7). Memperkenalkan dan mempertahankan stuktur dalam kegiatan-kegiatan yang teratur, 8). Berfungsi sebagai sumber kebahagiaan dan kesenangan, 9). Mendorong terjadinya hubungan sosial, dan 10). Menciptakan lingkungan yang terkendali dimana pengungkapan diri bisa diwujudkan. ${ }^{9}$

Musik dapat mengajarkan pada manusia tentang kebiasaan belajar yang baik, membantunya mengingatkan fakta-fakta dengan mudah baik secara visual dan aural dalam bergerak, mencipta dan berinteraksi dengan kelembutan dan kepekaan dalam mengekspresikan emosi dan membebaskan diri dari stress, memunculkan rasa senang dan lebih mudah menghafal kosa kata, apalagi musik diselingi dengan permainan bahasa yang dilengkapi dengan media elektronik seperti tape recorder, VCD, gambar dan sebagainya. ${ }^{1}$ Musik yang digunakan ${ }^{0}$ pada pembelajaran untuk pemula dapat melalui lagu dengan gerakan, isi nyanyian pendek dan mudah untuk dilafalkan. ${ }^{1}$

8 Ade Destri Deviana. Pengembangan Pembelajaran Bahasa Arab Berbasis Pendidikan Karakter Pada Anak Usia Dini. Jurnal Al Maqoyis Jilid 4 2016. h, 32

9 John Ortiz. Nurturing Your Child With Music. Jakarta: Gramedia Pustaka Utama, 2002. h, 180

1 H.R. Taufiqurrahman. Bolajar Bahasa Arab Melalui Lagu. Laporan Hasil Penelitian. UIN Maulana Malik Ibrahi Malang. 2007. Hal 6

1 Zukhaira. Pengenalan Bahała Arab melalui Nyanyian pada Anak Usia Pra Sekolah Di TK Islam Mutiara Hati.Uness Journal. 2011. Tanpa hal. 


\section{METODE PENELITIAN}

Penelitian ini menggunakan kualitatif deskriptif. Melakukan observasi secara langsung pada kelas saat proses pembelajaran berlangsung. Peneliti sebagai partisipan observasi dengan peneliti sebagai pengajar pada kelas tersebut. Analisis menggunakan model Miles dan Hiberman yaitu pengumpulan data, reduksi data, penyajian data dan kesimpulan.

\section{HASIL PENELITIAN}

Dalam mengajarkan kalām, pengajar bisa menggunakan lagu sebagai sebagai media dalam pembelajaran. Lagu merupakan salah satu jenis seni suara, sebagai suatu jenis lagu, lagu yang baik menjadi menarik untuk didengarkan, dan biasanya suatu pesan yang panjang jika dibuat dalam bentuk lagu akan mudah diingat dan dihafal, begitupun dengan materi-materi yang pelajaran yang sulit dan rumit akan tetap menarik dan menjadi lebih mudah dipahami jika dikemas dalam bentuk lagu.

Lagu yang cocok sebagai media pembelajaran adalah lagu yang popular bagi pembelajar dan kosakatanya mudah ditirukan. Untuk pembelajaran kalam bahasa Arab ini penulis memilih lagu dengan judul روحي فداك (Rühi Fìdāk), lagu ini sudah banyak dikenal oleh pembelajar dan sudah tidak asing lagi di telinga pembelajar dan kontentnya tentang bab 3 dari kitab al-'arobiyyah lil hayah jilid 3. Liik Lagu dalam $(R \bar{u} h \bar{i}$ Fìdāk), Rūhi Fìdāk ditulis oleh mahasiswa bersama pengajar. Kemudian akan dipahami semua kosakata yang ada pada lirik lagu Rūhỉ Fìdāk. Kosa kata pada lirik akan digunakan dalam percakapan. Pengajar dapat juga menggunakan musik lagu Rūhi Fỉdāk untuk membuat percakapan antara 2 orang anak sebagai lirik. Lirik yang dibuat dipraktikkan oleh anak secara berkelompok. Seperti yang sudah disusun di bawah ini: 
Nurul Hikmah: Pembelajaran Kalam Dengan Media Musik (Lagu)

Contoh percakapan bahasa Arab yang di lagukan dengan lagu ruhi fidak :

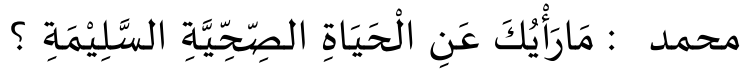

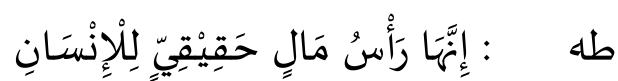

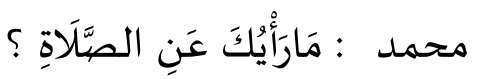

$$
\begin{aligned}
& \text { طها فِيْ أيّ نَظَر يَا محمد ؟ } \\
& \text { محمد : فى دِرَاستاتِ عِلْمِيَّةٍ صِحِيََّّة }
\end{aligned}
$$

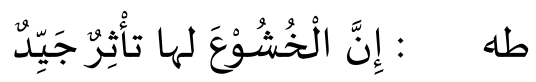

$$
\begin{aligned}
& \text { محمد : عَلَى ما يا طاه ؟ } \\
& \text { طها : على الشِيّفَاء يا محمد } \\
& \text { محمد : مِمَّا تخفض ممارسة العِبادة؟ } \\
& \text { طه : من ضغط الدم يا محمد } \\
& \text { محمد : وما أيضيا يا طه } \\
& \text { طه من هُرْمونات الْإِجْهَادِ } \\
& \text { محمد : ماذا ترى عن معظم الأمراض في هذا العصر ؟ } \\
& \text { طه : عدم تغيير أنماط اليومية الخاطئة } \\
& \text { محمد : مالأشياء الضرورية لأنماط الحياة الصحية ؟ } \\
& \text { طه : الإبتعاد عن السلوكيات الخطيرة التي قد تضر الصحة } \\
& \text { محمد : ما السلوكيات الخطيرة ؟ } \\
& \text { طه : مثلا إدمان الكحوليات } \\
& \text { محمد : وما أيضا يا طه ؟ } \\
& \text { طه : المخدرات يا محمد و استهلاك السجائر وإقامة العلاقات خارج إطار الزواج }
\end{aligned}
$$


Proses pelaksanaan pembelajaran sebagai berikut:

\section{Pendahuluan}

\section{(Pra Berbicara)}

a) Memberikan salam dan memulai pelajaran dengan basmalah.

b) Mengetahui kehadiran mahasiswa.

c) Memberikan apersepsi dengan membangun pengetahuan awal tentang berbicara. Pengajar mengupayakan mahasiswa menyampaikan pengalaman-pengalaman berbicaranya agar tumbuh keyakinan pada diri sendiri bahwa mampu dalam berbicara. Sebagai motivasi dan semangat dalam proses pembelajaran ini, Pengajar mengajak mahasiswa menyanyikan lagu yang mereka hafal secara dominan.

d) Menyampaikan kompetensi dari materi yang akan diajarkan

\section{Kegiatan inti}

\section{(Berbicara)}

a) Mahasiswa memperhatikan lagu/musik yang ditampilkan pengajar pada LCD dengan bantuan pengeras suara. Mahasiswa sekali-kali akan menirukan lagu tersebut.

b) Mahasiswa memperhatikan lagu yang diubah liriknya dan memahami isi/lirik lagu denagn bantuan penyampaian mufradat baru yang terdapat pada lirik oleh pengajar.

c) mahasiswa menyiapkan buku tulis, alat tulis, dan melafalkan lirik. Pengajar membimbing untuk mempersiapkannya.

d) Mahasiswa mengetahui kosakata baru. Pengajar memberikan kosa kata baru yang terdapat dalam materi.

e) Mahasiswa mengamati materi berbentuk teks yang dapat membantu mereka melafalkan lirik 
f) Mahasiswa mendengarkan penjelasan pengajar mengenai lirik lagu yang berkaitan struktur jumlahnya pada lirik.

g) Mahasiswa mempraktikkan lagu secara bersama sama. Pengajar mendampingi.

h) Mahasiswa mengamati materi menyampaikan pendapat, pertanyaan, dan saran-saran yang berkaitan dengan lirik. Pengajar memberikan mahasiswa keluasan dalam penyampaian pendapat.

i) Mahasiswa memperaktekkan bersama temannya. Pengajar mengamati, membenarkan dan memberikan perhatian.

\section{Kegiatan penutup}

a) Pengajar memberikan kesempatan mahasiswa untuk menanyakan tentang materi yang belum dapat dipahami.

b) Pengajar bersama mahasiswa menyimpulkan kegiatan berbicara

c) Pengajar mengevaluasi mahasiswa

Penggunaan lagu sebagai media pembelajaran Kalam ini disesuaikan dengan materi yang diajarkan dan disukai oleh pembelajar. Dengan media lagu semacam ini pembelajaran menjadi tidak membosankan, pembelajaran bisa berjalan rileks, tidak menegangkan, tidak monoton, dan materi bisa dikuasai pembelajar dengan mudah dan menyenangkan. Banyak lagu-lagu yang bisa digunakan sebagai media pembelajaran.

\section{SIMPULAN}

Lagu sebagai media pembelajaran kalām merupakan terobosan baru dari pengajar bahasa Arab agar pembelajaran bahasa Arab lebih fresh dan rileks. Caranya adalah dengan mengganti lirik lagu dalam 
konteks ini adalah lagu Ruhhî Fìd $\bar{a} k$ dengan hiwār (percakapan) yang disesuaikan dengan materi yang ada dalam kitab atau dengan kata lain mengembangkan hiwār yang ada di kitab menjadi sebuah lagu yang menarik. Isi hiwār menggunakan mufradat-mufradat yang dipelajari, termasuk mufradāt jadidah. Pembelajaran kalām dengan menggunakan media lagu menjadikan pembelajaran tidak membosankan, pembelajaran bisa berjalan rileks, tidak menegangkan, tidak monoton, dan materi bisa dikuasai pembelajar dengan mudah dan menyenangkan.

\section{DAFTAR PUSTAKA}

Baroroh, R. Umi., Lagu Sebagai Model Pembelajaran Bahasa Arab untuk Anak dan Pemula. Yogyakarta: Pustaka Zeedny, 2011.

Deviana, Ade Destri. Pengembangan Pembelajaran Bahasa Arab Berbasis Pendidikan Karakter Pada Anak Usia Dini. Jurnal Al Maqoyis Vol 4 No 12016.

Djohan. Psikolog Musik. Yogyarkata: Indonesia Cerdas, 2005.

Fachrurrozi, Aziz dan Erta Mahyuddin. Teknik Pembelajaran Bahasa Arab. Bandung: Pustaka Cendikia, 2011.

Gintings, Abdorrakhman. Esensi Praktis Belajar dan Pembelajaran, Bandung: Humaniora. 2010.

Hasan, Hasan. Keterampilan Mengajar Bahasa Arab Materi istima Menggunakan Media Lagu. Al Qalam: Jurnal Ilmiah Keagamaan dan Kemasyarakatan 10, no. 19, 2017.

Hasan, Hasan. Media Musik (Lagu) Dalam Pembelajaran Bahasa Arab Tingkat MI Al Qalam: Jurnal Ilmiah Keagamaan dan Kemasyarakatan, Vol. 9, No. 17, 2016.

Hasan, Hasan. Media Musik dan Lagu dalam Pembelajaran Bahasa Arab, Banjarmasin: Dreamedia. 2016. 
Nurul Hikmah: Pembelajaran Kalam Dengan Media Musik (Lagu)

Jumaryatun, dkk.. Penggunaan media lagu Sebagai Upaya meningkatkan Motivasi dan kemampuan menulis cerpen. Basaastra Jurnal Penelitian Bahasa Sastra Indonesia dan Pengajarannya Vol 1 No 3 Ortiz. John. Nurturing Your Child With Music. Jakarta: Gramedia Pustaka Utama, 2002.

Rahmaini. Strategi Pembelajaran Maharah Kalam Bagi Non Arab. Jurnal Ihya Ul Arabiyyah Vol 2 Tahun 2011.

Sari, Rahardani.. Musik Dan Kecerdasan Otak Bayi. Bogor: Buku Akasara, 2005.

Stephanus, Hermawan S. Mudah Membuat Aplikasi Android. Yogyakarta: Andi Offset, 2015

Taufiqurrahman, H.R. Belajar Bahasa Arab Melalui Lagu. Laporan Hasil Penelitian UIN Maulana Malik Ibrahim Malang, 2007.

Zukhaira, Zukhaira, Pengenalan Bahasa Arab Melalui Nyanyian pada Anak Usia Pra Sekolah Di TK Islam Mutiara Hati. Uness Journal. 2011. 